\title{
The prevalence of house dust mite (HDM) allergy and the use of HDM-impermeable bed covers in a primary care population of patients with persistent asthma in the Netherlands
}

\author{
M.P. de Vries ${ }^{a, *}$, L. van den Bemt ${ }^{a, b}$, F.M. van der Mooren ${ }^{a}$, \\ J.W.M. Muris ${ }^{a}$, C.P. van Schayck ${ }^{a}$
}

a Department of General Practice, Research Institute Caphri, Maastricht University, P.O. Box 616,
6200 MD Maastricht, The Netherlands
b Department of General Practice, University Medical Centre Nijmegen, Tine IJ etherlands

Received 2 March 2005; accepted 11 April 2005

KEYWORL'S

Allergic asthma;

House dust mite

allergens;

Primary care

\begin{abstract}
Summaro
Lackground: House dust mite (HDM) allergen is one of the most common allergens to which asthma patients are sensitised. Prevalence of HDM allergy varies in the literature. Use of HDM-impermeable bed covers reduces exposure to HDM allergen. The aim of this study was to assess the prevalence of HDM allergy in a primary care population of asthma patients, as well as the use of HDM-impermeable bed covers by these patients.

Methods: A random sample of asthma patients between 16 and 60 years old was taken from general practices. Allergy was assessed with a radio allegro sorbent test (RAST). A questionnaire was used to identify demographic characteristics and the actual use of bed covers.

Results: 534 patients were invited and 160 patients participated. 53 patients not willing to participate were randomly selected to test the external validity of our findings. The sample was representative for the primary care asthma population. $48.8 \%$ of the asthma population was sensitised to HDM allergen. $25.6 \%$ of the HDMallergic asthma patients were using HDM-impermeable bed covers.

Conclusion: Almost half of the patients with asthma were sensitised to HDM allergen. Only a minority of the patients used HDM-impermeable bed covers.

(c) 2005 General Practice Airways Group. Published by Elsevier Ltd. All rights reserved.
\end{abstract}

\footnotetext{
* Corresponding author. Tel.: +31 43 3882300; fax: +31433619344.

E-mail address: marjolein.devries@hag.unimaas.nl (M.P. de Vries).
}

\section{Introduction}

House dust mite (HDM) allergen is one of the most common allergens to which asthma patients are 
sensitised [1,2]. Exposure to HDM allergen can result in bronchoconstriction and an inflammatory reaction of the airways [3]. Up to $85 \%$ of atopic asthmatic patients may have HDM allergy, but these figures vary widely in the literature from 45 to $85 \%$ $[1,4,5]$.

HDM allergen avoidance measures are available in daily care. People spend approximately one third of their lives in bed. Therefore, HDM in mattresses, bedding and pillows contribute considerably to total HDM exposure [6,7]. Use of HDM-impermeable bed covers results in a considerable reduction in concentration of HDM allergen levels in bed [8-11]. Although the clinical efficacy of covers is still under debate [12] and some studies do not find a clinical benefit from covers [11,13], other studies show promising effects $[10,14-16]$. These differences in study outcomes may be partially explained by differences in study population, duration of follow up, baseline exposure to allergens, and medication use. In some studies assessing the efficacy of bed covers, patients were included who were not sensitised to HDM allergen. HDM avoidance measures seem especially effective as an early prevention measure in allergic patients who do not yet have a clinical diagnosis of asthma $[17,18]$.

Health policy and various guidelines suppo $c$ the use of HDM-impermeable covers ind fferent countries [19-21]. In severlat ccuntries, including the Netherlanding ins rande companies are reif. bursing the cust of bed covers Mhen H Div allergy is diagnosed. As a consequence, this ought to encourage widespread use of bed covers by allergic asthmatic patients in the Netherlands. However, it is uncertain to what extent HDM-allergic asthmatic patients are using these covers at the moment.

The aim of this study was to assess the prevalence of HDM allergy in a primary care population of adult asthmatic patients in the Netherlands. In addition, the use of HDM-impermeable covers in this asthma population was determined.

\section{Methods}

Asthma patients aged between 16 and 60 who were using inhaled steroids were selected from 15 general practices in the Netherlands. All subjects were invited to participate in a trial to test the effect of HDM-impermeable covers. With the invitation letter they received a questionnaire about the use of HDM-impermeable covers. If they were willing to participate, a radio-allergosorbent test (RAST) for specific immunoglobulin E (IgE) to HDM allergen was performed to test if subjects were sensitised to HDM. IgE levels above $0.35 \mathrm{kU} / \mathrm{l}$ were considered to be positive for HDM allergy. Moreover, patients received a questionnaire on their educational and employment level, smoking habits and medication use. Socioeconomic status (SES) was derived from educational and employment level. Both educational level and employment level were divided into the categories low, middle and high. SES was calculated as the mean of employment and educational level and also divided into the categories low, middle and high. Smoking was defined as current smoking, exsmoking or never smoking.

This questionnaire was also sent to a sample of patients not willing to participate in the trial, to compare characteristics between the study group and non-participants in order to assess the external validity of the sample studied. A random sample of $10 \%$ of the total number of patients invited to the trial was produced with assistance from a randomisation program. The two groups were compared on the following variables: gender; age; smoking status; and socio-economic status.

The Medical Ethical Committee of the University Hospital Maastricht approved the lajal, and all responders willing to (participate gave written informed colnsent. As s mple of patients who were prisilaly not willing to participate in the trial, volunteered todcrifote the patient characteristics que tiondire.

\section{Statistical analysis}

The percentages of patients sensitised to HDM allergen and patients using HDM-impermeable bed covers were calculated. The patient characteristics of participants and non-participants are presented as percentages or mean with $95 \%$ confidence intervals. Variables were compared by means of a Student's t-test or a chi-square-test, depending on the type of variable, to see whether there were any significant differences between participants and non-participants. Statistical significance was defined as $p$-value $<0.05$. Statistical analyses were performed with SPSS for Windows, Version 11.0.

\section{Results}

\section{HDM sensitisation}

Five hundred and thirty four asthma patients from 15 practices were invited to participate in the trial. 160 patients were willing to participate. From the group of patients not willing to participate a random sample of 53 patients completed the 
Table 1 Patient characteristics of the participants and a random sample of non-participants

\begin{tabular}{llll}
\hline & Participants $(N=160)$ & Non-participants $(N=53)$ & $p$-value \\
\hline Age in yrs (SD) & $41.5(13.2)$ & $35.4(12.6)$ & 0.004 \\
Gender M/F in (\%) & $47.8 / 52.2$ & $41.5 / 58.5$ & 0.448 \\
Smoking (\%) & & & \\
Current smoking & $43(26.9)$ & $10(18.9)$ & 0.115 \\
Ex-smoking & $48(30.0)$ & $12(22.6)$ & \\
Never smoking & $66(41.3)$ & $31(58.5)$ & \\
Missing & $3(1.9)$ & 0 & 0.292 \\
SES (\%) & & & \\
Low & $63(39.4)$ & $17(32.1)$ & \\
Middle & $66(41.3)$ & $29(54.7)$ & \\
High & $27(16.9)$ & $7(13.2)$ & \\
Missing & $4(2.5)$ & 0 & \\
\hline
\end{tabular}

SD: standard deviation, M: male, F: female, SES: socio economic status.

patient characteristics questionnaire. The results of the comparison on patient characteristics between the participants and non-participants are shown in Table 1.

There was a statistically significant difference in age between participants and non-participants ( $p$-value 0.004$)$. The other variables did not differ significantly.

The RAST test was performed in 160 petients. 78 patients $(48.8 \%)$ had a posirive test for HDM

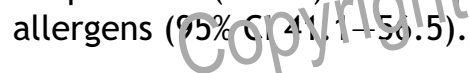

\section{Use of covers}

In the total group of responders the use of HDM-impermeable bed covers was $12.5 \%(95 \% \mathrm{CI}$ 9.3-15.7). With our prevalence figure for HDM allergy of $48.8 \%$, this implies that the use of HDMimpermeable covers is $25.6 \%(95 \% \mathrm{Cl} 18.8-32.4)$ in the HDM-allergic asthma patients. If the data on the use of HDM-impermeable covers and prevalence of HDM allergy are extrapolated to the total asthmatic population, this would suggest that almost $75 \%$ of asthmatic patients allergic to HDM do not use HDMimpermeable bed covers.

\section{Discussion}

This study shows that $48.8 \%$ of this population of asthma patients is sensitised to HDM. In the literature, 45 to $85 \%$ of asthmatic patients have been shown to be HDM allergic $[1,4,5]$. Accordingly, our figure of $48.8 \%$ is at the lower end of the range. In a population of more severe asthma patients a higher prevalence might be expected, and also in asthmatic children a higher prevalence is to be expected.

We found the estimated use of HDMimpermeable bed covers by HDM-sensitised asthma patients to be $25.6 \%$. Several HCiv-impermeable covers have been tested fefore with promising results of reduction of HDM allergen exposure 1] $[6,1,22-24]$. Therefore it is likely that the covers pat ierlts are using are actually reducing altergenl exposure. This study shows that there is room for improvement in HDM-impermeable bed cover use in asthmatic patients with HDM allergy. These numbers were extrapolated from the use of bed covers in the whole group of responders together with the prevalence of sensitisation to HDM allergen, assuming that only patients sensitised to HDM allergen are using bed covers. It could be that in the total group of responders patients not sensitised are using covers. Furthermore, patients could possess covers but not be using them. The estimated figure of $25.6 \%$ could therefore be an overestimation, suggesting that there is even more room for improvement. An underestimation seems very unlikely.

Nevertheless, at least $75 \%$ of HDM-allergic asthmatic patients using inhaled steroids are not using HDM-impermeable bed covers, even though the use of these covers could lead to better lung function and less symptoms $[10,14,16,25]$. A wide range of reasons for not using these covers can be assumed. Patients may not be aware of the benefits of HDM-impermeable covers or the effect covers might have on their asthma. Furthermore, patients might have had negative experiences with uncomfortable covers. As manufacture techniques progress this reason should be a passing concern. 
Moreover, patients may not be aware of the fact that insurance companies compensate the cost of the covers.

In addition, doctors might not prescribe HDMimpermeable bed covers because of various reasons: firstly, not all patients are examined for the presence of HDM allergy; and secondly, although possible benefits of HDM-impermeable bed covers are described in the literature, there are also studies showing no benefit from covers, as summarized in a Cochrane Review [12]. The negative effects might be explained by the fact that in some studies patients not sensitised to HDM allergens were included, or that other sensitising allergens were present and patients were actually exposed to these allergens; for example, patients sensitised to cat dander allergen, with a cat in the house, participating in a trial investigating the effects of HDM-impermeable covers. Apart from exposure to HDM allergen, exposure to other triggers or allergens can cause symptoms $[26,27]$. In this study we focused specifically on HDM allergen.

The patients who were willing to participate were representative with regard to gender, smoking status and socio-economic status of the average asthmatic population in primary care. However, the participants were older than the sample of no: participants (average age 41 years cortipared to 35 years.) In younger patikn's on=could expect a higher predaience bf HDik allergy. Howerel, Ive think that any prevalence differe. ce. between two groups with mean ages 41 and 35 will be minimal, and that the group of patients in which we assessed the prevalence of HDM allergy is representative for patients with mild to moderate asthma between the ages of 16 and 60 .

In conclusion, the prevalence of HDM allergy in this group of asthma patients in primary care was almost $50 \%$, which is at the lower end of the range compared to other studies. The actual use of HDM-impermeable covers in these HDM-allergic asthmatic patients was around $25 \%$.

\section{Conflicts of interest}

None declared.

\section{Acknowledgements}

This work was supported by a grant from the Netherlands Organisation for Scientific Research, the Netherlands Asthma Foundation and AstraZeneca BV and Boehringes Ingelheim.

\section{References}

[1] Dust mite allergens and asthma: a worldwide problem. International Workshop report. Bull World Health Organ 1988;66(6):769-80.

[2] Platts-Mills TAE, Vervloet D, Thomas WR, Aalberse RC, Chapman MD. Indoor allergens and asthma: report of the third international workshop. J Allergy Clin Immunol 1997;100(6):S1-24.

[3] Bush RK. The role of allergens in asthma. Chest 1992;101(6 Suppl):378S-80S.

[4] Smith JM, Disney ME, Williams JD, Goels ZA. Clinical significance of skin reactions to mite extracts in children with asthma. Br Med J 1969;1(659):723-6.

[5] Colloff MJ, Ayres J, Carswell F, Howarth PH, Merrett TG, Mitchell EB, et al. The control of allergens of dust mites and domestic pets: a position paper. Clin Exp Allergy 1992;22(Suppl 2):1-28.

[6] Marks BGB, Tovey ER, Green W, Shearer M, Salome CM, Woolcock AJ. The effect of changes in house dust mite allergen exposure on the severity of asthma. Clin Exp Allergy 1995;25:114-8.

[7] Garrett MH, Hooper BM, Hooper MA. Indoor environmental factors associated with house-dust-mite allergen (Der $p$ 1) levels in south-eastern Australian houses. Allergy 1998;53:1060-5.

[8] Hegarty JM, Jessop WJ, Warner JA, Warner JO. The effect of a bed covering system on iimborne level; of house dust mite allergen. Allergy $1015 ; 4:$ : 113 .

[9] Owen S, Mo's=istein M, Hepworth J, Woodcock A. cint of of nouse dust mite antigen in bedding. Lancet 4990;335(8686):3\% - 1

[10] Van rier Pieide], Kúurfman HF, Dubois AE, De Monchy JG. 11. ergen reduction measures in houses of allergic asthmatic patients: effects of air-cleaners and allergen-impermeable mattress covers. Eur Respir J 1997;10(6):1217-23.

[11] Rijssenbeek-Nouwens LHM, Oosting AJ, de Bruin-Weller MS, Bregman I, de Monchy JG, Postma DS. Clinical evaluation of the effect of anti-allergic mattress covers in patients with moderate to severe asthma and house dust mite allergy: a randomised double blind placebo controlled study. Thorax 2002;57:784-90.

[12] Gotzsche PC, Johansen HK, Schmidt LM, Burr ML. House dust mite control measures for asthma. The Cochrane Database \& Systematic Reviews 2004(4): AA. No.: CD 00 1187. pub 2. DOI:10.1002/14651858. CD 00 1187. pub 2.

[13] Woodcock A, Forster L, Matthews E, Martin J, Letley L, Vickers $M$, et al. Control of exposure to mite allergen and allergen-impermeable bed covers for adults with asthma. N Engl J Med 2003;349(3):225-36.

[14] Walshaw MJ, Evans CC. Allergen Avoidance in House Dust Mite Sensitive Adult Asthma. Q J Med 1986;226(New Series 58):199-215.

[15] Halken S, Niklassen U, Hansen LG, Nielsen F, Host A, Osterballe 0 , et al. Encasing of mattress in children with asthma and house dust mite allergy. J Allergy Clin Immunol 1997;99:S320.

[16] Van den Bemt L, Van Knapen L, De Vries MP, Jansen $M$, Cloosterman S, Van Schayck CP. Clinical effectiveness of a mite allergen-impermeable bed-covering system in asthmatic mite-sensitive patients. J Allergy Clin Immunol 2004;114(4):858-62.

[17] Cloosterman SGM, Hofland ID, Lukassen HGM, Wieringa MH, Folgering HTM, Heide SVD, et al. House dust mite avoidance measures improve peak flow and symptoms in patients with allergy but without asthma: A possible delay in the 
manifestation of clinical asthma? J Allergy Clin Immunol 1997; 100:313-9.

[18] Cloosterman SGM, Van Schayck OCP. Effectiveness of measures depends on stage of asthma. BMJ 1999;318:870.

[19] Asthma management and prevention. Global Initiative for Asthma. Ir Med J 2000;Suppl:i-vi, 1-39.

[20] BTS/SIGN British Guideline on the Management of Asthma. Thorax 2003;58(supplement 1):1-83.

[21] Geijer RMM, Van Hensbergen W, Bottema BJAM, Van Schayck CP, Sachs APE, Smeele IJM, et al. NHG-Standaard Astma bij Volwassenen: Behandeling (NHG Guideline on Asthma in Adults: Treatment). Huisarts Wet 2001;44(4):153-64.

[22] Terreehorst I, Hak E, Oosting AJ, Tempels-Pavlica Z, de Monchy JG, Bruijnzeel-Koomen CA, et al. Evaluation of impermeable covers for bedding in patients with allergic rhinitis. N Engl J Med 2003;349(3):237-46.

[23] Van der Heide S, Kauffman HF, Dubois AE, De Monchy JG. Allergen-avoidance measures in homes of house-dust- mite-allergic asthmatic patients: effects of acaricides and mattress encasings. Allergy 1997;52(9):921-7.

[24] Schonberger HJAM, Dompeling E, Knottnerus JA, Maas T, Muris JWM, van Weel C, et al. The PREVASC study: the clinical effect of a multifaceted educational intervention to prevent childhood asthma. Eur Respir J 2005;25(4):660-70.

[25] Halken S, Host A, Niklassen U, Hansen L, Nielsen F, Pedersen $S$, et al. Effect of mattress and pillow encasings on children with asthma and house dust mite allergy. J allergy Clin Immunol 2003;111:169-76.

[26] Custovic A, Taggart SCO, Francis HC, Chapman MD, Woodcock A. Exposure to house dust mite allergens and clinical activity of asthma. J Allergy Clin Immunol 1996;98(1):64-72.

[27] Platts Mills TA, Thomas WR, Aalberse RC, Vervloet D, Champman MD. Dust mite allergens and asthma: report of a second international workshop. J Allergy Clin Immunol 1992;89(5):1046-60.

Available online at www.sciencedirect.com

science $\boldsymbol{D}$ Direct.

Available online at http://www.thepcrj.com

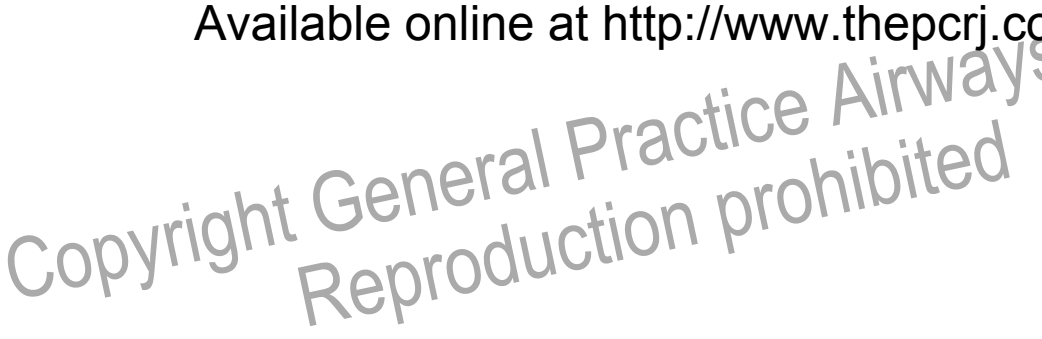

